\title{
VOLTAIRE - An EU V framework programme
}

\author{
Silas Chr. Michaelides*1 (Guest Editor) and Andreas Chlond ${ }^{2}$ \\ ${ }^{1}$ Meteorological Service of Cyprus, Nicosia, Cyprus \\ ${ }^{2}$ Max-Planck-Institut für Meteorologie, Hamburg, Germany
}

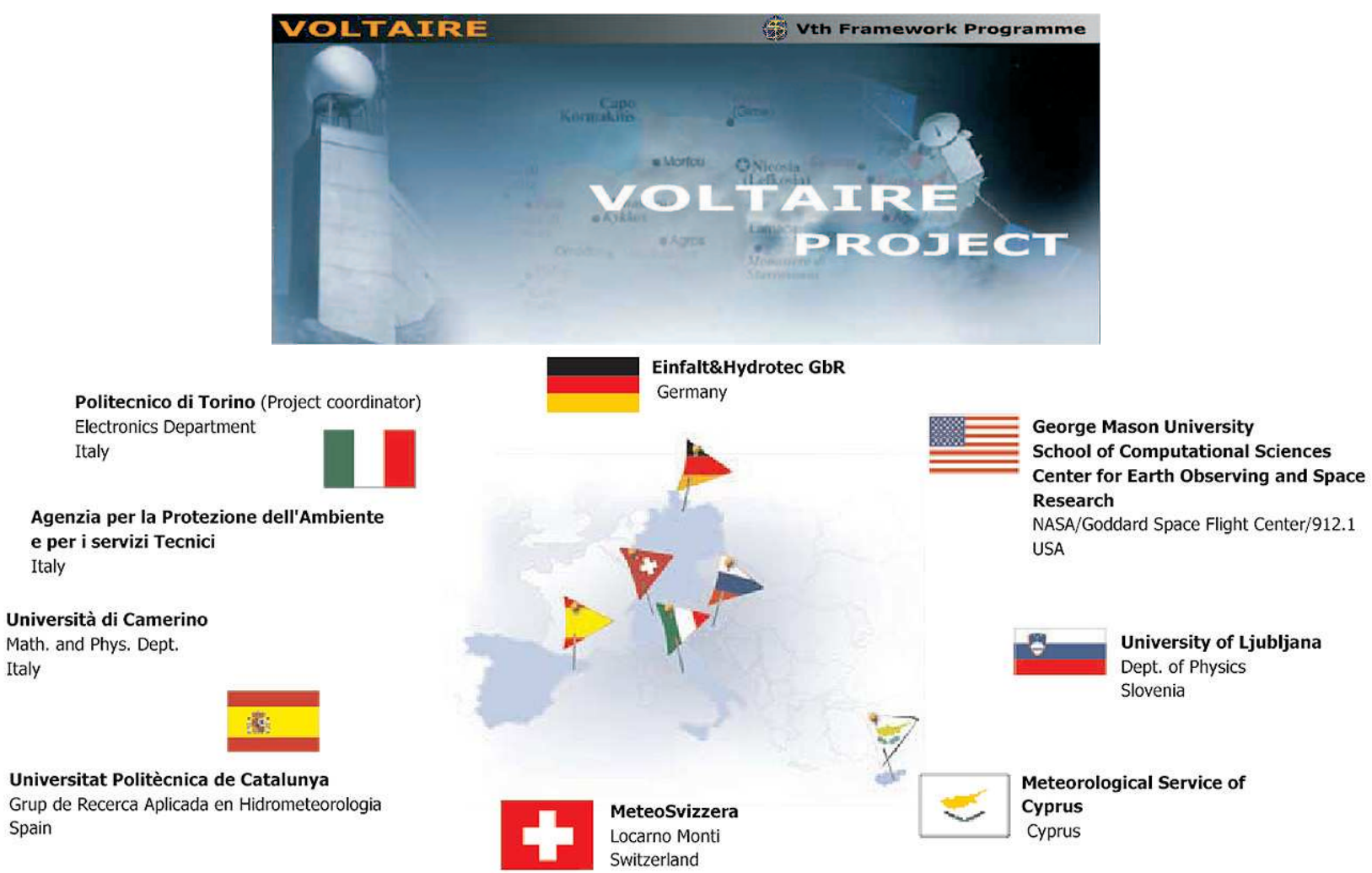

VOLTAIRE is the acronym of 'Validation of multisensors precipitation fields and numerical modeling in Mediterranean test sites. It is a research and technological development project within the EU V Framework Programme (Part A Environment and Sustainable Development - Key Action 2 "Global change, climate and biodiversity" - Contract No. EVK2-2001-00273).

Precipitation is much quite variable in both time and space. Reliable long-term records or fields with high spatio-temporal resolution exist only over the Earth's land areas and even there, the coverage is far from complete. As its descriptive title suggests, within VOLTAIRE, precipitation is treated as a multisensor issue: it is "observed" not only by conventional in situ point measurements (i.e. rain gauges) but, most of all, by using meteorological radars both at ground level and from space.

*Correspondence address: Silas Chr. Michaelides, Meteorological Service, Nicosia, Cyprus, e-mail: silas@ucy.ac.cy 
The main objectives of the project are:

- to compare data quality assurance schemes for ground and space radars;

- to use radar-gauge adjusted precipitation fields as ground validation for TRMM (Tropical Rainfall Measuring Mission) radar, in order to assure its data validity in areas that are not covered by ground radar;

- to gain experience and prepare European participation in GPM (Global Precipitation Mission);

- to improve the accuracy of surface-radar-derived precipitation fields in Mediterranean test sites using in situ measurements and adjustment techniques tailored to mountainous and hilly regions;

- to quantitatively compare precipitation fields as represented by numerical models, by adjusted ground-radar and satellite radar (where available, i.e. in Cyprus).

The consortium of VOLTAIRE comprises eight research establishments from six European countries (Italy, Germany, Cyprus, Spain, Switzerland and Slovenia) and one from the United States of America.

This Special Issue of Meteorologische Zeitschrift hosts selected papers presented at the VOLTAIRE Final Conference, which was held during the EMS/ECAM Conference in Utrecht, the Netherlands, in September 2005. The papers reflect most of the activities carried out during the project, presenting major findings and results.

The editors wish to express their gratitude to the twenty-eight anonymous reviewers who offered valuable assistance in selecting, upgrading and improving the papers presented in this Special Issue.

\section{Foreword}

Rain is certainly one of the meteorological quantities that most directly affects human life, much more than the other key quantities that characterize the weather from a physical point of view, e.g. pressure, humidity, temperature. On the one hand rain is important for every day life, in agriculture, in causing disasters, but on the other, it is not well known, as it is so difficult to measure and to forecast quantitatively. The rain field is much more complex and more variable in time and space than, for instance, pressure or temperature, which, instead, can be measured with a much higher accuracy. The multi-fractal nature of the rain field is certainly very poorly characterized either by conventional instruments (rain gauges), by long-range weather radar or by new spaceborne radar like TRMM Precipitation Radar. These are the reasons why the EC is promoting projects related to rain aspects in its various forms, from the lack of it (droughts) to the excess of it (floods, erosions). In this context, the VOLTAIRE project is probably the most comprehensive up to date research and technological development project that has specifically been related to a systematic study of various representations of rain fields and rain-related topics, namely:

- rain field characterization in complex environments such as mountainous terrain and the Mediterranean area;

- quantitative precipitation estimation using various measuring systems: rain gauge networks, ground-based meteorological radars and space-borne weather radar.

- comparisons between rain forecasting and rain observations.

- design of a ground validation site for the future Global Precipitation Measuring mission.

The results obtained within VOLTAIRE, which have been published in international journals, in this special issue on Meteorologische Zeitschrift and presented in conferences, will certainly have to be taken into account by researchers operating in other rain-related EC projects of the VII Framework Programme. However, the complex multi-fractal structure of rain fields still needs to be thoroughly characterized with new instruments for a better understanding of rain related phenomena of interest to a wider public (droughts, floods, erosion). 